\title{
DIGITALCOMMONS
}

$11-1-2007$

\section{A Note on Probability Trees}

W.J. Hurley

Royal Military College of Canada, hurley-w@rmc.ca

Follow this and additional works at: http://digitalcommons.wayne.edu/jmasm

Part of the Applied Statistics Commons, Social and Behavioral Sciences Commons, and the Statistical Theory Commons

\section{Recommended Citation}

Hurley, W. J. (2007) "A Note on Probability Trees," Journal of Modern Applied Statistical Methods: Vol. 6 : Iss. 2 , Article 28. DOI: $10.22237 /$ jmasm/1193891220

Available at: http://digitalcommons.wayne.edu/jmasm/vol6/iss2/28 


\title{
Brief Reports \\ A Note on Probability Trees
}

\author{
W. J. Hurley \\ Royal Military College of Canada
}

Not many introductory probability and statistics textbooks emphasize the use of probability trees to make complex probability calculations. This is puzzling in view of the power that trees bring to organizing such calculations for students. An effective classroom technique is discussed is this note.

\section{Introduction}

Not many introductory probability and statistics textbooks emphasize the use of probability trees to make complex probability calculations, including classics such as Hogg and Craig (1970), Parzen (1960), and Ross (1996). An exception is Aczel (1993). This is puzzling in view of the power that trees bring to organizing such calculations for students.

On the first day of a statistics course (both undergraduate and graduate) I teach, students are given a fairly complex real-world probability problem involving an assessment about whether a particular quality assurance test for an ammunition component is reasonable. After four weeks of lectures on introductory probability theory including probability trees and the binomial distribution, students are asked to revisit the problem for homework, and most are able to make the calculation and are very pleased for being able to do so.

\section{The Problem}

Here is a statement of the problem used in the first lecture, pertaining to defense resource management:

William Hurley is a Professor in the Department of Business Administration at the Royal Military College of Canada. His research interests are military operations research, decision analysis, and game theory. Email: hurley-w@rmc.ca
The primary armament on the Canadian Forces (CF) LAV III (Light Armored Vehicle) is the Bushmaster 242 Cannon. It fires $25 \mathrm{~mm}$ rounds in three-round bursts at enemy thinskinned assets. To be able to see where rounds go so that aim can be adjusted, each round comes with tracer. The tracer is the explosive charge that lights up for a brief period of time after the round is fired.

The CF purchases $25 \mathrm{~mm}$ ammunition in lot sizes of 5,000 and 10,000 rounds. Each lot must be tested to make sure that it satisfies the quality standards specified in the purchase contract. In almost all cases these specifications are governed by operational considerations. If ammunition is not up to specifications, soldiers in an operational environment are put at a higher risk. The specification for the $25 \mathrm{~mm}$ tracer is that it work $97.5 \%$ of the time. That is, the defective rate can be no more than $2.5 \%$. To test whether a lot satisfies this specification, the CF performs the following test.

A random sample of 10 rounds from a lot are fired. If there are 0 or 1 defective, the lot is accepted. If there are 3 or more defectives, it is rejected. If there are 2 defectives, another random sample of 10 rounds is fired. If there are 0 defective in this second sample, the lot is accepted; if there is 1 or more, it is rejected. 
The Weapon Systems Engineer has asked you to determine whether this is a good test. He is worried about accepting a lot when the actual defective rate is higher than $2.5 \%$. When you asked about defective rates, he stated that a $5 \%$ defective rate for the tracer was unacceptable and a $10 \%$ defective rate was absolutely unacceptable. You are required to assess the CF's chances of accepting a bad lot and report your results to the engineer. Use your intuition to assess whether the chance of accepting a bad lot is high or low.

Students are usually split on whether the probability is high or low and this may be a reflection of the uncertainty they have about the correct answer. Nonetheless, as officers and future officers in the Canadian Forces, they see the value of the problem and want to know how to solve it.

\section{Solution}

Over the first month, students are taught how to make probability calculations, including Bayes' Theorem using probability trees. A standard approach is taken, using simple problems such as picking marbles out of urns. With some repetition and homework, most students are able to pick up the mechanics of probability tree calculations very quickly. Once they have the idea with these simple problems, they are given real-world problems, most of which are based on my experience within the Department of National Defense and the Canadian Forces. The problem in the previous section is an example. The problems given for homework are a little different in that students are asked to make some specific calculations. Hence, the closing paragraph as follows:

The Weapon Systems Engineer has asked you to determine whether this is a good test. He is worried about accepting a lot when the actual defective rate is higher than $2.5 \%$. When you asked about defective rates, he stated that a $5 \%$ defective rate for the tracer was unacceptable and a $10 \%$ defective rate was absolutely unacceptable. You are required to assess the CF's chances of accepting a bad lot and report your results to the engineer. What is the chance of accepting the lot if the underlying defective rate is $5 \%$ ? What is the chance of accepting the lot if the underlying defective rate is $10 \%$ ?

Some students, particularly at the graduate level, will come to my office to see if they have done it properly. Because homework is not graded, it is presumed that they are genuinely interested in the solution strategy.

A tree for this problem is shown in Figure 1 where the base probabilities are shown on each arc. In this diagram, the binomial probability of exactly $\mathrm{x}$ successes in 10 trials is represented with $b(x)$. Accepting the lot happens along the top arc of the first stage (0 or 1 defective) and along the combination of the middle arc in the first stage and the top arc in the second stage ( 2 defective on the first sample and 0 defective on the second). Hence, to get the probability of accepting the lot, $\phi_{A}$, multiply probabilities along each path and then add the results:

$$
\phi_{A}=b(0)+b(1)+b(2) b(0) .
$$

Letting $p_{D}$ be the probability of a defective, we have that

$$
\begin{aligned}
& b(0)=C(10,0) p_{D}^{0}\left(1-p_{D}\right)^{10-0}=\left(1-p_{D}\right)^{10} \\
& b(1)=C(10,1) p_{D}^{1}\left(1-p_{D}\right)^{10-1}=10 p_{D}\left(1-p_{D}\right)^{9} \\
& b(2)=C(10,2) p_{D}^{2}\left(1-p_{D}\right)^{10-2}=45 p_{D}^{2}\left(1-p_{D}\right)^{8}
\end{aligned}
$$

and therefore

$$
\begin{gathered}
\phi_{A}=\left(1-p_{D}\right)^{10}+10 p_{D}\left(1-p_{D}\right)^{9} \\
+45 p_{D}^{2}\left(1-p_{D}\right)^{8}\left(1-p_{D}\right)^{10} .
\end{gathered}
$$

Table 1 shows values of $\phi_{A}$ for $p_{D}=0.05$ and 0.10 : 
Table 1

$\begin{array}{ll}p_{D} & \phi_{A} \\ .05 & .959 \\ .10 & .804\end{array}$

Note: Note that the probabilities of accepting a bad lot are very high. Consequently, the conclusion is that this test is not very good.

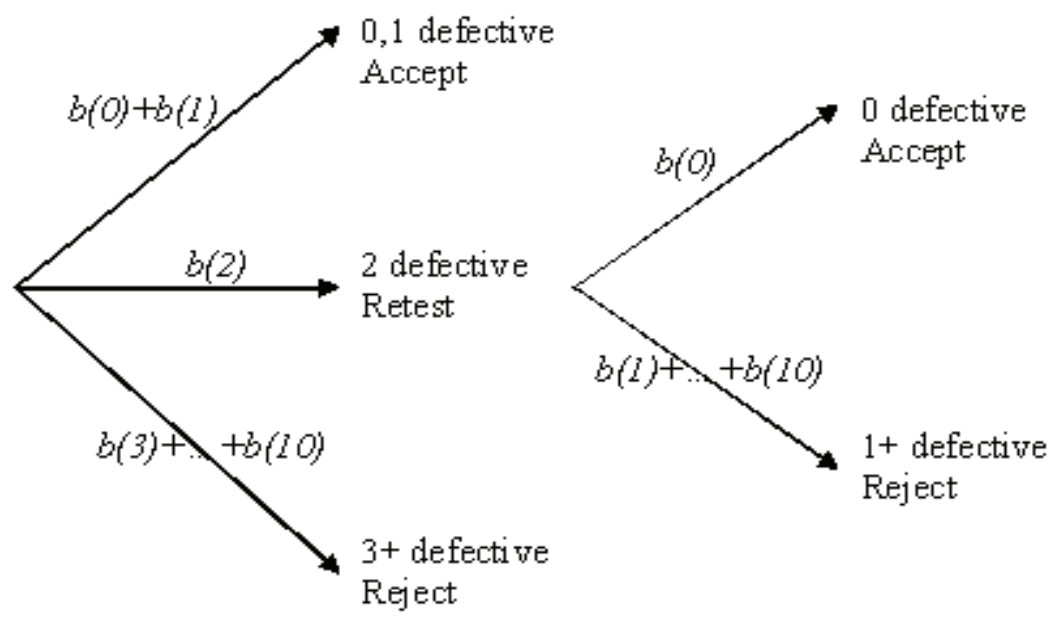

Figure 1. The Probability Tree

There are a number of interesting questions that can be asked at this point. For instance:

1. Regarding operational risk and the maximum $2.5 \%$ defective rate, if the underlying defective rate is actually $10 \%$, what is the chance that at least 2 tracers in a burst of three rounds will fire properly (another tree)?
2. How could this test be modified to produce a more favorable result?

To answer this question, students must consider two risks: supplier risk, the risk of rejecting a good lot of ammunition; and soldier risk, the risk of accepting a bad lot of ammunition. Obviously, from the point of view of the Canadian Forces, more weight would be put on soldier risk. This question is usually only pursued with graduate students and by giving specific direction. 
Summary

The best feedback I have had on probability trees has come from my graduate students. Most are officers in the Canadian Forces and have an undergraduate engineering degree with at least an introductory course in mathematical statistics. They indicate probability trees are much easier to use that the standard analytic approach. This is particularly true for conditional probability and Bayes' Rule. The problem presented here is particularly rich. It leads to interesting follow-on questions that can be explored either in the classroom or on assignments.

\section{References}

Aczel, Amir, Complete Business Statistics, Irwin, Chicago, 1996.

Hogg, R. V. and A. T. Craig, Introduction to Mathematical Statistics, Macmillan, New York, 1970.

Parzen, Emanuel, Modern Probability Theory and Its Application, Wiley, New York, 1960.

Ross, S. M., Introduction to Probability Models, Academic Press, Boston, 1993. 